\title{
Clinical management of gastroesophageal junction tumors: past and recent evidences for the role of radiotherapy in the multidisciplinary approach
}

\author{
Francesco Cellini ${ }^{*}$, Alessio G Morganti ${ }^{2,3}$, Francesco M Di Matteo ${ }^{4}$, Gian Carlo Mattiucci ${ }^{3}$ and Vincenzo Valentini ${ }^{3}$
}

\begin{abstract}
Gastroesophageal cancers (such as esophageal, gastric and gastroesophageal-junction -GEJ- lesions) are worldwide a leading cause of death being relatively rare but highly aggressive. In the past years, a clear shift in the location of upper gastrointestinal tract tumors has been recorded, both affecting the scientific research and the modern clinical practice. The integration of pre- or peri-operative multimodal approaches, as radiotherapy and chemotherapy (often combined), seems promising to further improve clinical outcome for such presentations. In the past, the definition of GEJ led to controversies and confusion: GEJ tumors have been managed either grouped to gastric or esophageal lesions, following slightly different surgical, radiotherapeutic and systemic approaches. Recently, the American Joint Committee on Cancer (AJCC) changed the staging and classification system of GEJ to harmonize some staging issues for esophageal and gastric cancer. This review discusses the most relevant historical and recent evidences of neoadjuvant treatment involving Radiotherapy for GEJ tumors, and describes the efficacy of such treatment in the frame of multimodal integrated therapies, from the new point of view of the recent classification of such tumors.
\end{abstract}

Keywords: Gastroesophageal, Gastric, Esophageal, Review, Radiotherapy, Radiochemotherapy, Chemoradiation, Tumor, Chemotherapy, Management

\section{Introduction}

Gastroesophageal cancers (such as esophageal, gastric and gastroesophageal junction -GEJ- lesions) are worldwide a leading cause of death, being relatively rare but highly aggressive [1]. Gastric carcinoma was reported as the second cause of cancer-related deaths worldwide [2], and esophageal cancer as the sixth one [3]. In the past years, a clear change of the more frequent locations of upper gastrointestinal (GI) tract tumors has been recorded [1] both affecting the scientific research and the modern clinical practice [4].

Frequency of the stomach's subsite in which cancer originates, has changed in the recent decades in Western countries [5]. The incidence of cancer of the distal stomach has decreased, while the incidence rate for cancers

\footnotetext{
*Correspondence: f.cellini@unicampus.it

'Radiation Oncology, Policlinico Universitario Campus Bio-Medico, Via Álvaro del Portillo, 200, 00144 Rome, Italy

Full list of author information is available at the end of the article
}

of the cardia and GEJ has been on a rapid upsurge [6]. Similarly, the most common site of esophageal cancer is the distal one, which often involves the gastroesophageal junction (GEJ) [1]. In developed countries, the incidence of gastric cancer originating from the cardia follows that of the esophageal cancer $[7,8]$, suggesting similar behaviors.

Anatomically, the GEJ is the burden separating the lower esophagus from the proximal part of the stomach, typically in the area where the squamous epithelium of esophagus changes into the columnar epithelium of gastric cardia [9]. Adenocarcinomas of the GEJ represent around $90 \%$ of all the GEJ cancers [10], they are generally considered to present lower radiosensitivity than squamous cell carcinomas, but still clear evidences for the specific subset of GEJ tumors are lacking.

Worldwide, the increased incidence of GEJ lesion is homogeneous among western countries like USA, Canada, Sweden, UK and most parts of Europe. The incidence of adenocarcinomas of GEJ, cardia and esophagus increased 
4-10\% each year since 1976 in USA among men [7,11,12]. Similarly, in Canada an increase of incidence of distal esophageal and proximal gastric adenocarcinomas was recorded from 1964 to 2002 [13]. In contrast, among Eastern Asian countries, the non-gastroesophageal lesions are predominant; as well, squamous cell carcinomas are more frequent than adenocarcinomas [14].

There is a variable incidence of such disease in terms of gender, sex, risk factors and geographical areas of incidence, being Caucasian, male and over 40 years old the most affected subgroup of patients. Predominant risk factors include: gastroesophageal reflux disease (GERD), Barrett's esophagus and obesity, followed by alcohol abuse and smoking $[10,15]$.

Recent ameliorations of surgical techniques have gained better results over last decades; nevertheless outcomes after resection are still poor, ranging by $20-30 \%$ of survival at 5 years, and optimization is needed [16]. The integration of pre- or peri-operative multimodal approaches, such as radiotherapy (RT) and chemotherapy (CT) (also combined), is promising to further improve clinical outcome for such presentations [17].

Purpose of this review is to discuss the most relevant historical and recent evidences on neoadjuvant treatment involving RT for GEJ tumors (in particular Phase III trials), and to describe its efficacy among multimodal integrated therapies, from the point of view of the new classification.

\section{Classification and staging of gastroesophageal junction tumors}

In past, GEJ cancers were alternatively considered as those related with a gastric or esophageal subsite since lying at the anatomical boundary of these two primary sites [18]. Also in clinical trials, GEJ tumors have been managed either grouped to gastric or to esophageal lesions, following slightly different surgical, radiotherapeutic and systemic approaches. Therefore, the definition of GEJ in past led to controversies and confusion [19]. Siewert and colleagues addressed an important attempt of classification for GEJ lesions. In the $80 \mathrm{~s}$, a first surgical classification based on clinical preoperative evaluation combining diagnostic and endoscopic features with intra-operative observations was proposed [20,21]. In this classification, three types of GEJ lesions were defined according to the localization of the lesion's epicenter. The three types of lesion were defined on the range of distance from the GEJ (more than $1 \mathrm{~cm}$ above, between $1 \mathrm{~cm}$ above and $2 \mathrm{~cm}$ below, over $2 \mathrm{~cm}$ below that). In the year 2000, the ranges of distance and the details of the definitions were slightly changed [22]. The current Siewert's classification is summarized in Table 1.

In 2006, the same group published the updated longterm results of their series on over 1600 patients [23]. Particularly, they highlighted different survival trends between the three subtypes, with better outcome for types I/II compared to type III. Moreover, they described the nodal spread for each type, particularly useful to guide both surgical dissection and radiotherapy planning (in terms of prophylactic nodal target definition).

The staging system adopted by the American Joint Committee on Cancer (AJCC) is more oriented by pathological findings. Recently, the staging system for GEJ changed, with the aim of harmonizing some staging issues about esophageal and gastric cancer [24]. The International Union Against Cancer (UICC) TNM Classification reports the same changes [25]. In the 7th UICC classification, GEJ tumors (i.e. the Siewert type I-II-III) are grouped as a subsite of esophageal cancer, whose epicenter is: in the distal esophagus, or in the GEJ, or as well within the proximal $5 \mathrm{~cm}$ of the stomach (cardia) if extending into the GEJ and distal esophagus. In summary, these three types of Siewert lesions together belong to esophagus according to the new classification. In particular, the Siewert type III lesion is not considered a subsite of gastric cancer any more (unless primary lesion originates within the first $5 \mathrm{~cm}$ of stomach but not infiltrating the gastroesophageal junction and esophagus).

Another important change applied by the 7th classification is related to the nodal staging definition. This is now defined by the number of pathologically involved nodes rather than by the location of the involved stations [24] since this issue strongly affects prognosis. For instance, in an experiment on 2920 patients, 5-year survival dropped from $63 \%$ in patients without nodal involvement, to $8 \%$ in patients with more than 6 pathologically positive nodes [26]. This approach follows the one already in use for gastric cancers [18]. According to some authors, the actual TNM classification does not completely solve the problems for GEJ lesions and remains object of debate, still presenting shortcomings in terms of clarity of interpretation [1].

Table 1 Siewert's classification for adenocarcinomas of GEJ

\begin{tabular}{cr}
\hline Siewert type & Epicenter of the lesion \\
\hline I & Within 1 to $5 \mathrm{~cm}$ above the anatomic GEJ \\
II & Within $1 \mathrm{~cm}$ above and $2 \mathrm{~cm}$ below the GEJ (i.e. true carcinoma of the cardia) \\
III & Between 2 to $5 \mathrm{~cm}$ below the GEJ, infiltrating GEJ and esophagus from below (subcardial carcinoma)
\end{tabular}


Some evidences suggest a common behavior between the recently grouped subsites from different points of view. The attention on the similarity of genetic mutation profiles between distal esophagus and GEJ adenocarcinomas is on rise [27].

The lymphatic spread behavior is of major interest in this regard: Leers et al. described in a recent paper the risk of nodal involvement for adenocarcinomas from different primary locations [28]. Two groups, one comprising 301 patients with distal esophagus lesions, and the other comprising 208 with GEJ tumors, showed similar rates of nodal spread ( $47 \%$ vs. $41 \%$ respectively); the distribution among the nodal station involved and the 5 year survival rates, according to the authors, were also similar. On the other hand, evidences from other series suggest a certain variance of aggressiveness within the GEJ classification, among the three Siewert types. More advanced histologic grades tend to be more frequent in types II and III than those in type I. Moreover, the percentage of involved nodes and the pattern of spread to nodal stations were reported to be slightly different, with a progressive increase of worse presentations from type I to type III [29]. In summary, there are data not only supporting the similarity of GEJ lesions to esophageal (as grouped by TNM classification), but also about the differences among different GEJ lesions on the basis of Siewert's classification. The nodal spread behavior not only represents a parameter of oncological similarity, and a well known risk factor strongly affecting survival [30-32]: it is also of major importance for radiation oncologist, addressing the treatment volume definition and consequently influencing efficacy and toxicity of RT. Following the surgical experience about anatomical spread types and nodal involvement rates [31,33], many attempts to indicate the optimal coverage of the areas at nodal risk were made for gastroesophageal lesions [34-36]. More recently, important studies from European working group (as the EORTC-ROG) as the one from Matzinger et al. [37] and single Institution experience [38], in line with the growing clinical importance of such an issue, have similarly deepened the GEJ lesions, suggesting the optimal target contouring for each Siewert's type based on risk of involvement. Such considerations support the need to consider both Siewert's classification and TNM staging tailoring therapies for the different tumor presentations.

\section{Clinical management Clinical background}

Surgery is a major component of treatment for resectable disease. Radical surgery is the most effective treatment modality, with the aim of the en-bloc removal of primary tumor and lymphatic nodes, obtaining microscopically negative resection margins (R0) [19].
In large historical surgical series, survival was strongly affected by the accomplishment of R0 resection: among 1602 patients, Siewert reported a 5-year survival rate of $43.2 \%$ vs. $11.1 \%$ for R0 and positive margins, respectively $(\mathrm{p}<0.0001)$ [23].

One of the major developments of surgery was the clear reduction in surgical morbidity and mortality as a result of improvements in staging techniques, patient selection and support therapies. Nowadays, surgery alone is mostly adopted for the treatment of early localized presentations [1].

The efficacy of neoadjuvant integrated treatments has been widely investigated over last the decades to overcome the poor outcome of more advanced presentations.

A recently published meta-analysis from 17 randomized trials including neoadjuvant RT, chemotherapy (CT) and surgery for esophageal carcinoma, strongly supported the adoption of combined-modality treatments [39]. Selected trials included both neoadjuvant CT and RT: the latter was administered as concomitant radiochemotherapy (RTCT) or following CT (in older studies). Results addressed a clear benefit from both RTCT $(\mathrm{p}<0.0001)$ and CT $(\mathrm{p}=0.005)$ over surgery alone, and a slightly non-significant trend favoring RTCT respect to CT $(\mathrm{p}=0.07)$. The absolute benefit was defined as an improvement of 2-year survival of $8.7 \%$ and $5.1 \%$ with RTCT and CT, respectively.

International Guidelines still do not completely agree on the standard treatment approach but basically suggest similar treatment options for adenocarcinoma of the esophagus (that nowadays the GEJ tumors belong to). The National Comprehensive Cancer Network (NCCN) recommends surgery alone for the very early presentations (i.e. Tis, T1a,T1bN0), and preoperative RTCT for all the others [1]. The National Cancer Institute (NCI) in its Physician Data Query (PDQ) suggests preoperative RTCT for presentation from Stage I to IV (non-metastatic) [40]. The European Society for Medical Oncology (ESMO) indicates: surgery for early presentations; perioperative chemotherapy for localized disease or, alternatively, preoperative RCTC. Preoperative RTCT and perioperative $\mathrm{CT}$ are recommended for locally advanced disease [41].

\section{Radiotherapy for gastroesphageal junction tumors:historical evidences}

Over the past 3 decades, the efficacy of RT for GEJ tumors was progressively clarified.

Arnott et al. in 1998 published a meta-analysis based on 5 available randomized trials of RT (associated to CT or not) versus Surgery [42]. They reported a nonstatistically significant absolute survival benefit of $3 \%$ at 2 years and $4 \%$ at 5 years (HR: 0.89; CI 0.78-1.01; $\mathrm{p}=$ 0.062). It has to be stressed that the global accrual period of the reported trials ranged from 1973 to 1988 , 
suggesting the use of older technology of treatment planning and dose delivery: some of the trials even used a Cobalt treatment unit. Moreover, the RT dose ranged from 20 to 40 Gy among the studies (lower than the most commonly used nowadays). The main characteristics of this and other meta-analyses mentioned in this review are summarized in Table 2.

Walsh et al. in 1996 published a landmark randomized study on esophageal tumors addressing the role of RT for GEJ adenocarcinomas. Cardiac tumors (at least considerable as Siewert II-III), or middle and lower third esophageal cancers (the latter is considerable at least in part as a Siewert I: details were not reported in detail by authors) [43]. This trial was not included in the Arnott's meta-analysis [42]. Between 1990 and 1995, 113 patients affected by adenocarcinoma were enrolled and randomized to either RTCT followed by surgery or surgery alone. The rate of patients affected by lesions of the middle third of the esophagus was $14.1 \%$, the remaining $85.9 \%$ are at least considerable GEJ in the modern classification. Patients in the experimental arm received RTCT (with 5-Fu and CDDP) up to a dose of 40 Gy (with 2.7 Gy per fraction in 15 fractions over 3 weeks). Of the 52 patients who underwent surgery in the RTCT arm, 13 (25\%) presented pathological complete response (pCR). Median survival was 16 and 11 months (mth) for preoperative RTCT and surgery-only arm $(\mathrm{p}=0.01)$, respectively. The 1-, 2- and 3-year survival rates were $52 \%$, $37 \%$, and $32 \%$ in the RTCT arm, and $44 \%, 26 \%$ and $6 \%$ in the surgery-only one, respectively $(\mathrm{p}=0.01)$.

Between 1998 and 1999, two randomized trials testing the superiority of RTCT over RT alone in the preoperative setting of esophageal tumors were published [44,45]. These studies are not really representative of GEJ adenocarcinomas due to their eligibility criteria. Smith $\boldsymbol{e t}$ al. enrolled approximately $50 \%$ of the patients with the primary site of tumor in the lower third of esophagus, but all patients presented SCC lesion; Cooper et al. enrolled all patients with primary site in the thoracic esophagus. Anyway, these trials encouraged the approach of following experiences for esophageal cancer, towards RTCT in the preoperative setting [17].

In 2001, Urba et $\boldsymbol{a l}$. published a randomized trial on preoperative RTCT versus surgery only [46] on patients presenting tumor of the esophagus or GEJ. It is difficult to precisely define the rate of GEJ tumor in patients enrolled in this trial, according to the modern definition. Ninetytwo percent of patients in both arms had a middle or lower third lesion, with a rate of upper third lesions lower than $10 \%$. Adenocarcinoma accounted for $75 \%$ (only $24 \%$ of squamous cell carcinoma). One hundred patients were enrolled from 1989 to 1994: 50 patients received RTCT with a total dose of 45 Gy (1.5 Gy per fraction, two fraction per day, over 21 days), concurrently with 5-FU, CDDP and vinblastine. In the surgery-only arm 90\% (45/50) had a gross total resection; and in the RTCT arm 95.7\% (45/47 who underwent surgery) had a gross total resection. In the experimental arm, $28 \%$ had a pCR (14/50, according to intention to treat). Median survival and 3-year survival for surgery and RTCT arms were 17.6 vs. $16.9 \mathrm{mth}$, and $16 \%$ vs. $30 \%(p=0.15)$, respectively. It has to be noted that this study was statistically powered to detect a relatively large increase in median survival, and that the dose fractionation and $\mathrm{CT}$ association differed from the more common standards. Interestingly, when considering the survival by pathological response, a clear significant benefit was found: the reported median survival and 3-year survival rate for the pCR group versus the non-pCR were 49.7 vs. $12 \mathrm{mth}$, and $64 \%$ vs. $19 \%$, respectively, highlighting the importance of preoperative effective treatment for responder patients.

Fiorica et al. in 2004 published a meta-analysis including 6 trials of RTCT versus surgery alone [47]. This study included the two papers by Walsh et al. and Urba et al. mentioned above.

Authors not only showed a significant survival benefit of neoadjuvant RTCT over surgery alone (HR: 0.53; CI: 0.310.92; $\mathrm{p}=0.03$ ), but also highlighted a significant risk for postoperative mortality. Two considerations should be addressed. First, the reported survival benefit was still not strong in itself. Survival evidence of benefit was lost for the exclusion from the statistical evaluation of either the study from Walsh, or the one from Urba. Therefore, the need for further evidence was clear. Second, the toxicity related to neoadjuvant RTCT was mainly due to the contribution of a trial by Bosset et al., using non-conventional RT doses and fractionations, also questioned by its Authors, and no longer used in the following experiences [17] (see also Table 2).

\section{Recent randomized trials of radio(chemo)therapy plus surgery versus surgery alone}

Burmeister et al. in 2005 [48] failed to report a significant benefit adding preoperative RTCT to surgery alone. Between 1994 and 2000, they randomized 256 patients. Lesions were cited in the proximal or middle esophagus for $23 \%$ in the RTCT arm and for $19 \%$ in the surgery alone one. Distal esophageal lesions (more representative for GEJ) accounted for $77 \%$ in the RTCT arm and for $81 \%$ in the surgery alone one. Primary lesions originating in cardia with predominant esophageal invasion (similar to Siewert III) were included. Adenocarcinomas were approximately $60 \%$ in both arms. RTCT delivered 35 Gy (in 15 fraction of 2.4 Gy over 3 weeks) with concurrent 5-FU and CDDP. RTCT was well tolerated: esophagitis was the highest Grade 3-4 toxicity, reported in 16\% of patients. There was no significant benefit for progression free and overall survival in the RTCT arm respect to the 
Table 2 Meta-analyses on preoperative treatment (RT; RTCT; CT) versus surgery

\begin{tabular}{|c|c|c|c|c|c|c|c|c|c|c|c|c|c|}
\hline & $\begin{array}{l}\text { Primary tumor } \\
\text { site }\end{array}$ & $\begin{array}{l}\text { Range of } \\
\text { recruitment } \\
\text { periods }\end{array}$ & $\begin{array}{l}\mathrm{N}^{\circ} \\
\text { trial }\end{array}$ & $\begin{array}{l}\mathrm{N}^{\circ} \text { trial } \\
\text { Including } \\
\mathrm{RT}\end{array}$ & $\begin{array}{l}\mathrm{N}^{\circ} \\
\text { total } \\
\text { pts }\end{array}$ & $\begin{array}{c}\mathbf{N}^{\circ} \text { pts } \mathrm{RT} \pm \mathrm{CT} \\
\text { arms }\end{array}$ & $\begin{array}{l}\mathrm{N}^{\circ} \\
\text { pts } \\
\mathrm{CT} \\
\text { arms }\end{array}$ & $\begin{array}{l}\mathrm{N}^{\circ} \text { pts } \\
\text { surgery } \\
\text { arms }\end{array}$ & $\begin{array}{l}\text { Dose } \\
\text { range } \\
\text { (Gy) }\end{array}$ & Hystology & $\begin{array}{l}\text { Hazard ratio } \\
(95 \% \mathrm{Cl} ; \mathrm{p})\end{array}$ & $\begin{array}{c}\text { SVV } \\
\text { benefit } \\
2 \text { yy }\end{array}$ & $\begin{array}{c}\text { SVV } \\
\text { benefit } \\
5 \text { yy }\end{array}$ \\
\hline \multirow[t]{2}{*}{ Arnott [42] } & Esophagus & 1973-1988 & 5 & 5 & 1147 & 573 & - & 574 & $20-40$ & SCC-86\% & 0.89 & $4 \%$ & $3 \%$ \\
\hline & & & & & & $\begin{array}{c}\text { (520 RT alone + } \\
\quad 53 \text { RTCT) }\end{array}$ & & & & ADC-14\% & $\begin{array}{c}(\mathrm{Cl} 0.78-1.01 ; \\
\mathrm{p}=0.06)\end{array}$ & & \\
\hline \multirow[t]{2}{*}{ Fiorica [47] } & Esophagus & 1983-1995 & 6 & 6 & 764 & 385 & - & 379 & $20-45$ & SCC-76\% & 0.53 & NS & NS \\
\hline & & & & & & & & & & $A D C-24 \%$ & $\begin{array}{c}(\mathrm{Cl} 0.31-0.92 ; \\
\mathrm{p}=0.03)\end{array}$ & & \\
\hline \multirow[t]{6}{*}{ Sjoquist [39] } & Esophagus & $1982-2008$ & 24 & 14 & 4188 & 1079 & 1046 & 2063 & $20-50.4$ & SCC- $48.9 \%$ & RTCT: 0.78 & RTCT: $8.7 \%$ & $N R$ \\
\hline & & & & & & & & & & & $\begin{array}{l}(\mathrm{Cl} 0.70-0.88 ; \\
\mathrm{p}<0.0001)\end{array}$ & & \\
\hline & & & & & & & & & & ADC-35.5\% & CT: 0.87 & CT: $5.1 \%$ & \\
\hline & & & & & & & & & & & $\begin{array}{l}(\mathrm{Cl} 0.79-0.96 \\
\mathrm{p}=0.005)\end{array}$ & & \\
\hline & & & & & & & & & & & RTCT vs CT: 0.88 & & \\
\hline & & & & & & & & & & & $\begin{array}{c}(\mathrm{Cl} 0.76-1.01 \\
\mathrm{p}=0.07)\end{array}$ & & \\
\hline \multirow{6}{*}{$\begin{array}{c}\text { Ronellenfitsch } \\
{[16]}\end{array}$} & Esophagus + & 1987-2004 & 14 & 4 & 2422 & 198 & 1024 & 1200 & $35-50.4$ & SCC- $0 \%$ & $\mathrm{CT}( \pm \mathrm{RT}): 0.81$ & NS & $\overline{C T}( \pm R T): 9 \%$ \\
\hline & & & & & & & & & & & $\begin{array}{l}(\mathrm{Cl} 0.73-0.89 ; \\
\mathrm{p}<0.0001)\end{array}$ & & \\
\hline & & & & & & & & & & ADC-100\% & RTCT: 0.70 & & \\
\hline & & & & & & & & & & & $\begin{array}{c}(\mathrm{Cl} 0.50-0.99 \\
\mathrm{p}=0.38)\end{array}$ & & \\
\hline & & & & & & & & & & & CT: 0.83 & & \\
\hline & & & & & & & & & & & $\begin{array}{c}(\mathrm{Cl} 0.75-0.91 \\
\mathrm{p}=0.38)\end{array}$ & & \\
\hline
\end{tabular}

[Pts: patients; Gy: Gray; pCR: pathological complete response; RT: Radiotherapy; CT: Chemotherapy; RTCT: radiochemotherapy; yy: years ; Cl: Confidence Interval; SVV: survival; SCC: Squamous Cellular Carcinoma; ADC: Adenocarcinoma; GEJ: Gastroesophageal Junction; NS: Not Specified; NR: Not Reported]. 
control one, even though a small trend favoring RTCT was reported. It is interesting to highlight that in the experimental arm, a significantly higher $\mathrm{R} 0$ resection rate $(80 \%$ vs. $59 \%$; $=0.0002)$, and lower rate of pathologically positive lymph-nodes $(43 \%$ vs. $67 \% ; \mathrm{p}=0.003)$ were reported. Patients in the RTCT arm reported $16 \%$ rate of pCR. It should be highlighted that the RT dose was lower than that in the other modern randomized trials that reported an outcome improvement.

In 2008, Tepper et al. published a trial on patients with esophageal or GEJ tumor (both squamous and adenocarcinomas) [49]. Lesions of the thoracic esophagus (below $20 \mathrm{~cm}$ ), and/or GEJ with less than $2 \mathrm{~cm}$ distal spread into the cardia (the latter corresponds to the actual Siewert II) were included. The rate of lesions in the thoracic esophagus was not specified, but $75 \%$ of the 56 enrolled patients had adenocarcinoma (orienting for a major presence of GEJ lesions). Between 1997 and 2000, 30 patients in the experimental arm received RTCT with a total dose of 50.4 Gy (45 Gy in extended field + 5.4 Gy as boost; conventional fractions over 5.5 weeks) plus concomitant 5-FU and CDDP. Grade 3-4 esophagitis was the highest non-hematological toxicity, reported in $26 \%$ for RTCT. Pathological data were available only for 25/30 patients in the RTCT arm: pCR was reported for $40 \%(10 / 25)$. At a median follow-up (fup) of 6 years, according to intent-to-treat analysis there was a significant survival benefit for RTCT over surgery alone. Median survival was 4.48 vs. 1.79 years and 5-year survival was $39 \%$ vs. $16 \%$ for RTCT and surgery alone, respectively $(p=0.002)$. The study was prematurely closed due to poor accrual (respect to the 475 planned), and suffered for this statistical bias.

Van Hagen et al. in 2012 published the "Chemoradiotherapy for esophageal cancer followed by surgery study" (CROSS) trial, advocated as potential gold standard for esophageal cancer [50]. Between 2004 and 2008, 366 patients affected with esophageal or GEJ carcinoma were enrolled. Pure GEJ lesions were reported in around 25\% of patients. Over $80 \%$ of the patients in both the arms had primary lesion cited in the distal third lesion or at the GEJ, and adenocarcinomas accounted for $75 \%$. RTCT consisted of a dose of 41.2 Gy (conventional fractionation, over 5 weeks) plus weekly Carboplatin and Paclitaxel. Tolerance to RTCT was good: $91 \%$ of patients in experimental arm received the full treatment regimen. In the RTCT group, 94\% of patients underwent surgery versus $99 \%$ in the control arm $(\mathrm{p}=0.01)$; seven patients in RTCT group showed disease progression during treatment, compared to one in the surgery-only group. An R0 resection was obtained for 148/161 patients (92\%) versus $111 / 161$ (69\%) in the RTCT and control group respectively $(\mathrm{p}<0.001)$. At a median fup of $45.4 \mathrm{mth}$, the 3 - and 5 -years overall survival rates were $58 \%$ vs. $44 \%$ and $47 \%$ vs. $24 \%$ for combined treatment and surgery alone arms, respectively $(\mathrm{p}=0.003)$.

Two of the most interesting pathological findings should be highlighted. The first is the $29 \%$ rate of pCR $(47 / 161)$ in the RTCT group, higher but in line with the previously published evidences for GEJ tumors. Second: the significantly lower presence of pathological nodal involvement in the RTCT compared to the surgery only arm: $31 \%$ vs. $75 \%$ respectively ( $\mathrm{p}<0.001)$.

In 2014, a specific analysis of the relation between the site of recurrence and radiation field in CROSS I and II trials was published [51]. Oppedijk et al. showed that RT significantly improved over surgery alone both locoregional recurrence $(14 \%$ vs. $34 \%$; $\mathrm{p}<0.001)$ and peritoneal carcinomatosis ( $4 \%$ vs. $14 \% ; \mathrm{p}<0.001)$, also presenting a small but significant benefit on hematogenous dissemination rates $(29 \%$ vs. $35 \% ; \mathrm{p}=0.025)$. Recurrences within the RT treatment volume occurred in only 5\% (11/213) evaluable patients.

The main randomized trials of RTCT plus Surgery versus Surgery alone are summarized in Table 3.

\section{Randomized trials of radio(chemo)therapy versus chemotherapy}

Two randomized trials recently compared RTCT versus $\mathrm{CT}$ in the preoperative setting.

Burmeister et al. randomized in a phase II trial, between 2000 and 2006, 75 patients presenting resectable adenocarcinoma of the esophagus and GEJ. The planned accrual was 100 patients, but was reduced due to poor accrual in the RTCT arm for technical reasons. Treatment consisted of either CT with 5-FU and CDDP, or RTCT delivering a dose of 35 Gy (in 15 fractions of 2.4 Gy over 3 weeks) concomitantly to the same drugs at reduced doses [52]. Similarly to their previous trial comparing RTCT to surgery alone [48], RT dose was lower than in other reported trials: again RTCT failed to significantly improve outcomes. Nevertheless, in the RTCT group a positive trend was reported for progression free survival (14mth-CT vs. 26 mth-RTCT; $\mathrm{p}=0.37$ ) and overall survival (29mth-CT vs. $32 \mathrm{mth}-\mathrm{RTCT} ; \mathrm{p}=0.83$ ). It is interesting that the RTCT approach gained significantly higher pathological response rates (RTCT 31\% versus CT 8\%; $p=0.01$ ) and $\mathrm{R} 1$ resection rates $(\mathrm{RTCT}$ $0 \%$ versus CT $11 \%$; $\mathrm{p}=0.04$ ). Toxicity profiles were similar in the 2 arms. The statistical power of this study should be interpreted with caution, especially in regard to progression free survival. Authors concluded that the most important evidence was about the not increased toxicity and the superior pathological response in the combined arm.

Stahl et al. published in 2009 a phase III trial on 126 patients (enrolled between 2000-2005) affected by adenocarcinoma of the lower esophagus and cardia (Siewert 
Table 3 Phase III randomized trials comparing radiochemotherapy plus surgery versus surgery alone

\begin{tabular}{|c|c|c|c|c|c|c|c|c|c|c|c|}
\hline & $\begin{array}{l}\mathbf{N}^{\circ} \\
\text { Pts }\end{array}$ & Accrual & $\begin{array}{l}\text { Rate } \\
\text { adeno }\end{array}$ & Tumor site & Dose/Fx (Gy) & $\begin{array}{l}\text { Concurrent } \\
\text { CT }\end{array}$ & $\begin{array}{c}\% \text { pCR } \\
\begin{array}{c}\text { (No pts RTCT } \\
\text { arm) }\end{array}\end{array}$ & $\begin{array}{c}3 \text { yy OS \% } \\
\text { [RTCT+ surg vs. } \\
\text { surg alone] }\end{array}$ & $\begin{array}{c}5 \text { yy OS \% } \\
\text { [RTCT+ surg vs } \\
\text { surg alone] }\end{array}$ & $\begin{array}{l}\text { Median SVV } \\
\quad(\mathrm{mth}) \\
\text { [RTCT+ surg vs } \\
\text { surg alone] }\end{array}$ & $\begin{array}{l}\text { Median fup } \\
\quad(\mathrm{mth})\end{array}$ \\
\hline Walsh [43] & 113 & $\begin{array}{l}1990- \\
1995\end{array}$ & $100 \%$ & $\begin{array}{c}\text { Middle+ Lower } \\
\text { Esophagus + Cardias }\end{array}$ & $40 / 2.7$ & $\mathrm{CDDP}+5 \mathrm{Fu}$ & $25 \%(13 / 52)$ & $\begin{array}{l}32 \text { vs. } 6 \\
(p=0.01)\end{array}$ & - & 16 vs 11 & $10(0.1-59)$ \\
\hline Urba [46] & 100 & $\begin{array}{l}1989- \\
1994\end{array}$ & $75 \%$ & $\begin{array}{l}\text { Proximal+ Middle + } \\
\text { Lower Esophagus + } \\
\text { GEJ }\end{array}$ & $\begin{array}{l}\text { 45/1.5 (twice } \\
\text { daily) }\end{array}$ & $\begin{array}{l}\text { CDDP+ 5Fu+ } \\
\text { Vimblastine }\end{array}$ & $28 \%(14 / 50)$ & $\begin{array}{l}30 \text { vs. } 16 \\
(p=0.15)\end{array}$ & - & 16.9 vs 17.6 & $98.4(72-118.8)$ \\
\hline $\begin{array}{c}\text { Burmeister } \\
\text { [48] }\end{array}$ & 256 & $\begin{array}{l}1994- \\
2000\end{array}$ & $62 \%$ & $\begin{array}{l}\text { Proximal +Middle+ } \\
\text { Lower Esophagus }\end{array}$ & $35 / 2.4$ & $\mathrm{CDDP}+5 \mathrm{Fu}$ & $16 \%(16 / 103)$ & $\begin{array}{l}42 \text { vs. } 36 \\
(p=0.57)\end{array}$ & 21 vs. 19 & 22.2 vs. 19.3 & $65(0.4-120)$ \\
\hline Tepper [49] & 56 & $\begin{array}{l}1997- \\
2000\end{array}$ & $75 \%$ & $\begin{array}{l}\text { Toracic Esophagus } \\
\text { (below } 20 \mathrm{~cm} \text { ) }+ \text { GEJ } \\
<2 \mathrm{~cm} \text { distal spread } \\
\text { in cardia }\end{array}$ & $50.4 / 1.8$ & $\mathrm{CDDP}+5 \mathrm{Fu}$ & $40 \%(10 / 25)$ & - & $\begin{array}{l}39 \text { vs. } 16 \\
(p=0.002)\end{array}$ & 53.8 vs. 21.5 & $72(\mathrm{NR})$ \\
\hline $\begin{array}{c}\text { Van Hagen } \\
{[50]}\end{array}$ & 366 & $\begin{array}{l}2004- \\
2008\end{array}$ & $75 \%$ & $\begin{array}{l}\text { Proximal +Middle+ } \\
\text { Lower Esophagus + } \\
\text { GEJ }\end{array}$ & $41.2 / 1.8$ & $\underset{\text { Paclitaxel }}{\text { Carboplatin + }}$ & 29\% (47/161) & $\begin{array}{l}58 \text { vs. } 44 \\
(p=0.003)\end{array}$ & 47 vs. 34 & 49.4 vs. 24 & $45.4(25.5-80.9)$ \\
\hline
\end{tabular}

[Pts: patients; Gy: Gray; pCR: pathological complete response; RTCT: radiochemotherapy; yy: years; OS: overall survival; Surg: surgery; SWV: survival; mth: months; Fup: follow-up; CDDP: Cisplatin; 5Fu: 5fluoruracil;. 
I-III) [53]. Treatment consisted of either 15 weeks of CT (with CDDP, 5-Fu, Leucovorin) or 12 weeks of the same CT followed by 3 weeks of RTCT (30 Gy with conventional fractionation plus CDDP and Etoposide). In the RTCT arm, a significant improvement of the pCR rate (RTCT: $15.6 \%$ vs. CT: $2.0 \% ; \mathrm{p}=0.03$ ) was reported. Also the tumor-free lymph-nodes rate was significantly higher in the RTCT group (RTCT: $64.4 \%$ vs. CT: $36.7 \%$; $\mathrm{p}=0.01$ ). Preoperative RT showed a positive non-significant trend in the 3-year survival rates (RTCT: $27.7 \%$ vs. CT: $47.4 \%$; $=$ 0.07). It is important to stress as the non significance of such results should be carefully interpreted for some reasons: the study was statistically designed to detect a $10 \%$ improvement in the 3 year survival for the RTCT arm, expecting a much larger accrual in each arm; almost a $20 \%$ of improvement was actually reported, but the total number of needed patients after the planned first stage of the protocol required 163 additional patients per arm, then the study was closed without obtaining the required statistical power. Moreover, the impact of the pathological findings reflected the subgroup survival analysis: the pathologically node-negative patients had a significantly higher 3 -year survival $(64.2 \%$ vs. $38.8 \%$; p < 0.001). Patients achieving pCR were all alive at the median follow-up time of 4.1 years, independently by administered treatment.

About the tolerance of preoperative RTCT, a nonsignificantly increased postoperative mortality in the RTCT arm $(10.2 \%$ vs. $3.8 \%$; $=0.26)$ was reported: this data is not completely in line with the others experiences in literature (in particular the available meta-analyses suggest a risk of postoperative morbidity slightly decreasing in the more recent trials), and the 12 weeks of CT induction before RTCT could have played a role.

A final consideration on the study by Stahl should be addressed about the absolute pCR rate reported in the RTCT arm. Even though the pCR rate in RTCT is significantly higher than that in the CT arm, it is considerably lower than that in the previously mentioned series. It is arguable (as suggested by the authors) that the low RT dose had an influence on that aspect. It could also be hypothesized that the choice of the RT dose was influenced by attempt to keep the overall duration of the RTCT treatment similar to the CT one (i.e. 15 weeks).

We have already highlighted, among the previously cited clinical experiences, that inducing a pCR after neoadjuvant treatment is crucial for the prognosis. This is a known issue, highlighted from historical series of specific experiences on both esophageal and gastric tumors [54-56]. That issue was also recently confirmed in one of the largest single center retrospective series, published by Fields et al. [57]. They reviewed cases from 714 patients treated between 1985 and 2009 at the Memorial Sloan-Kettering Cancer Center: all of them were treated with preoperative therapy (i.e. CT with or without RT) for localized gastric or GEJ adenocacinoma. On 714 treated patients, 609 had an R0 resection after preoperative treatment. The vast majority of R0 patients had GEJ lesion (359/609 $-60 \%$ of pure GEJ only; 439/ $609-72 \%$ of pure GEJ + proximal gastric lesions). A whole rate of $8.4 \%(60 / 609)$ of pCR was reported. These patients showed significantly lower rate of 5 -year recurrence compared to non-pCR patients (27\% versus $51 \%$; $\mathrm{p}=0.01$ ). It is arguable that the low absolute rate of $\mathrm{pCR}$ is due to the long time frame of evaluation, meaning older RT treatments and drugs administered.

Ronellenfitsch et $\boldsymbol{a l}$. published in 2013 a meta-analysis based on aggregate and individual patient data collecting randomized phase III trials comparing surgery alone versus surgery preceded by neoadjuvant treatment at least including CT (either alone or combined with RT). It summarizes some issues debated in this review. Authors collected 14 phase III trials on adenocarcinoma, of esophagus, GEJ or stomach: time to death from randomization, on an intention-to-treat base was the primary outcome [16]. They highlighted that administration of CT (globally evaluated as preoperative CT alone + RTCT) gained significantly longer survival respect to surgery alone, with an absolute benefit of $9 \%$ at 5-year survival (HR 0.81, CI 0.730.89; $\mathrm{p}<0.0001)$. Moreover, a longer disease free survival, higher down staging rate and R0 resection probability were reported. Preoperative therapy was not associated to higher postoperative complication likelihood. When separately analyzed by anatomical subsites, the reported results were largest for the GEJ presentations, followed by esophageal and gastric tumors. In direct subgroup analysis, RTCT showed a larger (but not significant) effect then $\mathrm{CT}$ in producing the survival benefit (HR: 0.70, CI 0.50-0.99 for RTCT vs. 0.83 , CI $0.75-0.91$ for CT; $\mathrm{p}=0.38$ ). Authors summarize that the available evidences suggest a benefit from adding RT to CT for adenocarcinoma of GEJ and esophagus.

It is also relevant to note that due to the timing of the meta-analysis, the CROSS trial from Van Hagen [50] was not included, and it is arguable that it could have enhanced the statistical power.

Sign of the interest and relevance of the issue of preoperative RTCT for adenocarcinoma of the pure GEJ is provided by the growing number of new clinical experiences focused on it, involving the new RT technologies, and providing positive results: Platz et al. reported in 2013 as intensity-modulated-RT (IMRT) up to 50 Gy plus CT, produced $100 \%$ of $\mathrm{R} 0$ resection rate and $38 \%$ of $\mathrm{pCR}$ in a group of 16 patients [58]. At a median follow-up of 15.3 mth (9.8-20), 3/16 patients had recurrence (1 anastomotic, 2 distant nodal). Moreover, some important PhaseII/III studies focused on preoperative RTCT on GEJ tumors are currently registered and on-going, as the TOPGEAR trial from the collaboration of EORTC -TROG (Identifier: 
NCT01924819), randomly evaluating perioperative CT associated or not to preoperative RTCT. At least 2 other studies are focused on preoperative RTCT in the specific population of GEJ lesion only lesions: one from a Chinese group in Hebei (Identifier: NCT01962246) evaluating RTCT versus CT alone for Siewert types II-III; the other from a Polish one in Lublin (Identifier: NCT01523015) comparing RTCT (for type I-II) or CT alone (for type III) plus surgery versus surgery alone. In line with the growing trend of research on the new molecular targeted agents for GEJ tumors, studies are on-going specifically recruiting patients with GEJ lesions. Many biologically targeted agents are under evaluation, but again the research scenario is still often recruiting GEJ tumors together with esophageal and gastric ones. Evidences seem more than promising, particularly oriented to drugs targeting EGFR, VEGF and HER, this last one seems one of the most promising agents based on the still few evidences from direct evaluation of these drugs in concomitant combination with RT [4]. Still more robust evidences are needed to clearly define the optimal strategy, moreover we must be aware of the difficulties in defining response profiles: attempts in this direction are addressed to individuate genetic signatures profiling the GEJ tumors $[59,60]$, their response to therapies [61] or specific genes and molecules potential candidates for new drug development [62]. Finally, also the presence of specific histological patterns as signet ring cells or mucinous histology could be predictive of worse prognosis and better response to RTCT $[63,64]$ and should be included in the treatment decision process or new trial setting, but evidences in this regard are still not conclusive [65].

\section{Conclusions}

Looking at the main evidences reported in literature about the role of RT in the multimodal management of GEJ adenocarcinomas, some problems are still evident in term of clarity of the classification, patient selections in the trial and evaluation of results. Nevertheless, we can summarize that the integration of preoperative RT before surgery is highly effective over surgery alone, providing significantly improved results in terms of local control and survival, with acceptable toxicity rates. In this setting, RT should be administered at least to a total dose of 40-45 Gy (with conventional fractionation), and associated to concomitant chemosensibilization. A nonsignificant positive trend gaining better results over preoperative CT alone is also reported in literature. To define the best treatment option, a new randomized trial, with a particular attention to accrual criteria, taking into account both TNM and Siewert's classification is needed. To tailor the future treatment approaches, it is crucial to consider the molecular profile of the disease and include the more promising new molecular targeted therapies, as well as considering the new option of RT delivering coming from new technologies.

\section{Abbreviations}

5-Fu: 5-Fluoruracil; CT: Chemotherapy; CDDP: Cisplatin; fup: Follow-up; GEJ: Gastroesophageal junction; GI: Gastrointestinal; GERD: Gastroesophageal reflux disease; mth: Month; OS: Overall survival; pCR: pathological complete response; RT: Radiotherapy; RTCT: Radiochemotherapy.

\section{Competing interests}

The authors declare that they have no competing interests.

\section{Authors' contribution}

FC: designed the paper setting, selected evidences, extracted data and drafted paper; AGM: supervised and edited the paper drafting, paragraph setting, and evidences selection;FMD: supervised the classification section; GM: supervised and edited the trial section; W: supervised and edited the paper setting and evidence selection; All authors read and approved the final manuscript.

\section{Author details}

'Radiation Oncology, Policlinico Universitario Campus Bio-Medico, Via Álvaro del Portillo, 200, 00144 Rome, Italy. ${ }^{2}$ Radiotherapy Department, Fondazione di Ricerca e Cura "Giovanni Paolo II", Largo Agostino Gemelli 1, 86100 Campobasso, Italy. ${ }^{3}$ Radiation Oncology Department, Policlinico Universitario "A. Gemelli", Universita` Cattolica del Sacro Cuore, L.go Francesco Vito 1, 00168 Rome, Italy. ${ }^{4} \mathrm{Gl}$ Endoscopy Unit, Policlinico Universitario Campus Bio-Medico University, Via Alvaro del Portillo 200, 00128 Rome, Italy.

Received: 31 October 2013 Accepted: 1 February 2014

Published: 5 February 2014

\section{References}

1. NCCN: NCCN guidelines - esophageal and esophagogastric cancers (excluding proximal $5 \mathrm{~cm}$ stomach). In NCCN clinical practice guideline in oncology - version 2.2013. Available at: http://www.nccn.org/professionals/ physician_gls/pdf/esophageal.pdf.

2. Moehler M, Gockel I, Roessler HP, Arnold D, Trarbach T, Thomaidis T, Klautke G, Rodel C, Brenner B, Lang H, et al: Prospective, open, multi-centre phase I/I trial to assess safety and efficacy of neoadjuvant radiochemotherapy with docetaxel and oxaliplatin in patients with adenocarcinoma of the oesophagogastric junction. BMC Cancer 2013, 13:75.

3. Yang L, Wang LS, Chen XL, Gatalica Z, Qiu S, Liu Z, Stoner G, Zhang H, Weiss $\mathrm{H}$, Xie J: Hedgehog signaling activation in the development of squamous cell carcinoma and adenocarcinoma of esophagus. Int J Biochem Mol Biol 2012, 3:46-57.

4. Cellini $F$, Valentini V: Targeted therapies in combination with radiotherapy in oesophageal and gastroesophageal carcinoma. Curr Med Chem 2013: [Epub ahead of print].

5. Blot WJ, Devesa SS, Kneller RW, Fraumeni JF Jr: Rising incidence of adenocarcinoma of the esophagus and gastric cardia. JAMA 1991, 265:1287-1289.

6. PDQ: $P D Q^{\circledR}$ Gastric cancer treatment. Bethesda, MD: National Cancer Institute. Date last modified 02/15/2013. Available at: http://cancer.gov/ cancertopics/pdq/treatment/gastric/HealthProfessional.

7. Crew KD, Neugut Al: Epidemiology of upper gastrointestinal malignancies. Semin Oncol 2004, 31:450-464.

8. Powell J, McConkey CC, Gillison EW, Spychal RT: Continuing rising trend in oesophageal adenocarcinoma. Int J Cancer 2002, 102:422-427.

9. Rusch WW: Are cancers of the esophagus, gastroesophageal junction, and cardia one disease, two, or several? Semin Oncol 2004, 31:444-449.

10. Buas MF, Vaughan TL: Epidemiology and risk factors for gastroesophageal junction tumors: understanding the rising incidence of this disease. Semin Radiat Oncol 2013, 23:3-9.

11. Devesa SS, Fraumeni JF Jr: The rising incidence of gastric cardia cancer. J Natl Cancer Inst 1999, 91:747-749.

12. $\mathrm{Ku} \mathrm{GY}$, Ilson DH: Chemotherapeutic options for gastroesophageal junction tumors. Semin Radiat Oncol 2013, 23:24-30.

13. Parfitt JR, Miladinovic Z, Driman DK: Increasing incidence of adenocarcinoma of the gastroesophageal junction and distal stomach in 
Canada - an epidemiological study from 1964-2002. Can J Gastroenterol = Journal canadien de gastroenterologie 2006, 20:271-276.

14. Ozawa S, Ando N, Kitagawa Y, Kitajima M: [Does incidence of carcinoma of the esophagogastric junction increase?]. Nihon Geka Gakkai zasshi 1998, 99:542-546.

15. Marsman WA, Tytgat GN, ten Kate FJ, van Lanschot JJ: Differences and similarities of adenocarcinomas of the esophagus and esophagogastric junction. J Surg Oncol 2005, 92:160-168.

16. Ronellenfitsch U, Schwarzbach M, Hofheinz R, Kienle P, Kieser M, Slanger TE, Burmeister B, Kelsen D, Niedzwiecki D, Schuhmacher C, et al: Preoperative chemo (radio) therapy versus primary surgery for gastroesophageal adenocarcinoma: systematic review with meta-analysis combining individual patient and aggregate data. Eur I Cancer 2013, 49(15):3149-3158. doi:10.1016/j.ejca.2013.05.029.

17. Cellini F, Ramella S, Ciresa M, Porziella V, Meacci E, Fiore M, Trodella L, D'Angelillo RM: Role of induction therapy in esophageal cancer. Rays 2005, 30:329-333.

18. Kleinberg L: Therapy for locally advanced adenocarcinoma of the gastroesophageal junction: optimizing outcome. Semin Radiat Oncol 2013, 23:38-50.

19. Amenabar A, Hoppo T, Jobe BA: Surgical management of gastroesophageal junction tumors. Semin Radiat Oncol 2013, 23:16-23.

20. Siewert JR, Holscher AH, Becker K, Gossner W: [Cardia cancer: attempt at a therapeutically relevant classification]. Chirurg 1987, 58:25-32.

21. Siewert JR, Stein HJ: Classification of adenocarcinoma of the oesophagogastric junction. Br J Surg 1998, 85:1457-1459.

22. Rudiger Siewert J, Feith M, Werner M, Stein HJ: Adenocarcinoma of the esophagogastric junction: results of surgical therapy based on anatomical/topographic classification in 1,002 consecutive patients. Ann Surg 2000, 232:353-361.

23. Feith M, Stein HJ, Siewert JR: Adenocarcinoma of the esophagogastric junction: surgical therapy based on 1602 consecutive resected patients. Surg Oncol Clin N Am 2006, 15:751-764.

24. Rice TW, Blackstone EH, Rusch WW: 7th edition of the AJCC cancer staging manual: esophagus and esophagogastric junction. Ann Surg Oncol 2010, 17:1721-1724.

25. Sobin L, Gospodarowicz M, Wittekind C: TNM classification of malignant tumors. 7th edition. Oxford: Wiley-Blackwell; 2009.

26. Gertler R, Stein HJ, Langer R, Nettelmann M, Schuster T, Hoefler H, Siewert $J R$, Feith M: Long-term outcome of 2920 patients with cancers of the esophagus and esophagogastric junction: evaluation of the New Union Internationale Contre le Cancer/American Joint Cancer Committee staging system. Ann Surg 2011, 253:689-698.

27. Isinger-Ekstrand A, Johansson J, Ohlsson M, Francis P, Staaf J, Jonsson M, Borg A, Nilbert M: Genetic profiles of gastroesophageal cancer: combined analysis using expression array and tiling array-comparative genomic hybridization. Cancer Genet Cytogenet 2010, 200:120-126.

28. Leers JM, DeMeester SR, Chan N, Ayazi S, Oezcelik A, Abate E, Banki F, Lipham JC, Hagen JA, DeMeester TR: Clinical characteristics, biologic behavior, and survival after esophagectomy are similar for adenocarcinoma of the gastroesophageal junction and the distal esophagus. J Thorac Cardiovasc Surg 2009, 138:594-602.

29. Kurokawa Y, Sasako M, Doki Y: Treatment approaches to esophagogastric junction tumors. Digestive surgery 2013, 30:169-173.

30. Lee JS, Douglass HO Jr: D2 dissection for gastric cancer. Surg Oncol 1997, 6:215-225.

31. Gunderson LL, Sosin H: Adenocarcinoma of the stomach: areas of failure in a re-operation series (second or symptomatic look) clinicopathologic correlation and implications for adjuvant therapy. Int J Radiat Oncol Biol Phys 1982, 8:1-11.

32. Kodera Y, Yamamura Y, Shimizu Y, Torii A, Hirai T, Yasui K, Morimoto T, Kato T, Kito T: Lymph node status assessment for gastric carcinoma: is the number of metastatic lymph nodes really practical as a parameter for $\mathrm{N}$ categories in the TNM classification? Tumor node metastasis. J Surg Oncol 1998, 69:15-20.

33. Japanese Gastric Cancer A: Japanese classification of gastric carcinoma 2nd English edition. Gastric Cancer 1998, 1:10-24.

34. Xiong HQ, Gunderson LL, Yao J, Ajani JA: Chemoradiation for resectable gastric cancer. Lancet Oncol 2003, 4:498-505.

35. Smalley SR, Gunderson L, Tepper J, Martenson JA Jr, Minsky B, Willett C, Rich T: Gastric surgical adjuvant radiotherapy consensus report: rationale and treatment implementation. Int J Radiat Oncol Biol Phys 2002, 52:283-293.
36. Cellini F, Valentini V, Pacelli F, D'Ugo D, Mantini G, Balducci M, Gambacorta MA, Nori S: Preoperative radiotherapy in gastric cancer: CTV definition for conformal therapy according to tumor location. Rays 2003, 28:317-329.

37. Matzinger O, Gerber E, Bernstein Z, Maingon P, Haustermans K, Bosset JF, Gulyban A, Poortmans P, Collette L, Kuten A: EORTC-ROG expert opinion: radiotherapy volume and treatment guidelines for neoadjuvant radiation of adenocarcinomas of the gastroesophageal junction and the stomach. Radiother Oncol 2009, 92:164-175.

38. Yi Y, Yu J, Li B, Yang F, Huang W, Sun H, Gong H, Zhou T, Lin H: Pattern of lymph node metastases and its implication in radiotherapeutic clinical target volume delineation of regional lymph node in patients with gastric carcinoma. Radiother Oncol 2010, 96:223-230.

39. Sjoquist KM, Burmeister BH, Smithers BM, Zalcberg JR, Simes RJ, Barbour A, Gebski V: Survival after neoadjuvant chemotherapy or chemoradiotherapy for resectable oesophageal carcinoma: an updated meta-analysis. Lancet Oncol 2011, 12:681-692

40. $\mathrm{PDQ}^{\bullet}$ : National Cancer Institute: $\mathrm{PDQ}^{\oplus}$ esophageal cancer treatment Bethesda, MD: National Cancer Institute. Date last modified 02/15/2013: Available at: http://cancer.gov/cancertopics/pdq/treatment/esophageal/ HealthProfessional.

41. Stahl M, Budach W, Meyer HJ, Cervantes A, Group EGW: Esophageal cancer: clinical practice guidelines for diagnosis, treatment and follow-up. Ann Oncol 2010, 21(Suppl 5):v46-v49.

42. Arnott SJ, Duncan W, Gignoux M, Girling DJ, Hansen HS, Launois B, Nygaard K, Parmar MK, Roussel A, Spiliopoulos G, et al: Preoperative radiotherapy in esophageal carcinoma: a meta-analysis using individual patient data (Oesophageal cancer collaborative group). Int I Radiat Oncol Biol Phys 1998, 41:579-583.

43. Walsh TN, Noonan N, Hollywood D, Kelly A, Keeling N, Hennessy TP: A comparison of multimodal therapy and surgery for esophageal adenocarcinoma. N Engl J Med 1996, 335:462-467.

44. Cooper JS, Guo MD, Herskovic A, Macdonald JS, Martenson JA Jr, Al-Sarraf M, Byhardt R, Russell AH, Beitler JJ, Spencer S, et al: Chemoradiotherapy of locally advanced esophageal cancer: long-term follow-up of a prospective randomized trial (RTOG 85-01). Radiation therapy oncology group. JAMA 1999, 281:1623-1627.

45. Smith TJ, Ryan LM, Douglass HO Jr, Haller DG, Dayal Y, Kirkwood J, Tormey DC, Schutt AJ, Hinson J, Sischy B: Combined chemoradiotherapy vs. radiotherapy alone for early stage squamous cell carcinoma of the esophagus: a study of the Eastern cooperative oncology group. Int J Radiat Oncol Biol Phys 1998, 42:269-276.

46. Urba SG, Orringer MB, Turrisi A, lannettoni M, Forastiere A, Strawderman M Randomized trial of preoperative chemoradiation versus surgery alone in patients with locoregional esophageal carcinoma. J Clin Oncol 2001, 19:305-313.

47. Fiorica F, Di Bona D, Schepis F, Licata A, Shahied L, Venturi A, Falchi AM, Craxi A, Camma C: Preoperative chemoradiotherapy for oesophageal cancer: a systematic review and meta-analysis. Gut 2004, 53:925-930.

48. Burmeister BH, Smithers BM, Gebski V, Fitzgerald L, Simes RJ, Devitt P, Ackland S, Gotley DC, Joseph D, Millar J, et al: Surgery alone versus chemoradiotherapy followed by surgery for resectable cancer of the esophagus: a randomized controlled phase III trial. Lancet Oncol 2005, 6:659-668.

49. Tepper J, Krasna MJ, Niedzwiecki D, Hollis D, Reed CE, Goldberg R, Kiel K, Willett C, Sugarbaker D, Mayer R: Phase III trial of trimodality therapy with cisplatin, fluorouracil, radiotherapy, and surgery compared with surgery alone for esophageal cancer: CALGB 9781. J Clin Oncol 2008, 26:1086-1092

50. Van Hagen P, Hulshof MC, van Lanschot JJ, Steyerberg EW, van Berge Henegouwen MI, Wijnhoven BP, Richel DJ, Nieuwenhuijzen GA, Hospers GA, Bonenkamp JJ, et al: Preoperative chemoradiotherapy for esophageal or junctional cancer. N Engl J Med 2012, 366:2074-2084.

51. Oppedijk V, van der Gaast A, van Lanschot JJ, Van Hagen P, van Os R, van Rij CM, van der Sangen MJ, Beukema JC, Rutten H, Spruit PH, et al: Patterns of recurrence after surgery alone versus preoperative chemoradiotherapy and surgery in the CROSS trials. J Clin Oncol 2014: [Epub ahead of print].

52. Burmeister BH, Thomas JM, Burmeister EA, Walpole ET, Harvey JA, Thomson DB, Barbour AP, Gotley DC, Smithers BM: Is concurrent radiation therapy required in patients receiving preoperative chemotherapy for adenocarcinoma of the esophagus? A randomised phase II trial. Eur J Cancer 2011, 47:354-360. 
53. Stahl M, Walz MK, Stuschke M, Lehmann N, Meyer HJ, Riera-Knorrenschild J, Langer P, Engenhart-Cabillic R, Bitzer M, Konigsrainer A, et al: Phase III comparison of preoperative chemotherapy compared with chemoradiotherapy in patients with locally advanced adenocarcinoma of the esophagogastric junction. J Clin Oncol 2009, 27:851-856.

54. Mandard AM, Dalibard F, Mandard JC, Marnay J, Henry-Amar M, Petiot JF, Roussel A, Jacob JH, Segol P, Samama G, et al: Pathologic assessment of tumor regression after preoperative chemoradiotherapy of esophageal carcinoma. Clinicopathologic correlations. Cancer 1994, 73:2680-2686.

55. Rohatgi PR, Swisher SG, Correa AM, Wu TT, Liao Z, Komaki R, Walsh G, Vaporciyan A, Lynch PM, Rice DC, et al: Failure patterns correlate with the proportion of residual carcinoma after preoperative chemoradiotherapy for carcinoma of the esophagus. Cancer 2005, 104:1349-1355.

56. Rohatgi PR, Mansfield PF, Crane CH, Wu TT, Sunder PK, Ross WA, Morris JS, Pisters PW, Feig BW, Gunderson LL, Ajani JA: Surgical pathology stage by American joint commission on cancer criteria predicts patient survival after preoperative chemoradiation for localized gastric carcinoma. Cancer 2006, 107:1475-1482.

57. Fields RC, Strong VE, Gonen M, Goodman KA, Rizk NP, Kelsen DP, Ilson DH, Tang LH, Brennan MF, Coit DG, Shah MA: Recurrence and survival after pathologic complete response to preoperative therapy followed by surgery for gastric or gastrooesophageal adenocarcinoma. $\mathrm{Br} J$ Cancer 2011, 104:1840-1847.

58. Platz TA, Nurkin SJ, Fong MK, Groman A, Flaherty L, Malhotra U, Levea CM, Yendamuri S, Warren GW, Nava HR, May KS: Neoadjuvant chemoradiotherapy for esophageal/gastroesophageal carcinoma. J Gastrointest Oncol 2013, 4:137-143.

59. Bashash M, Shah A, Hislop G, Treml M, Bretherick K, Janoo-Gilani R, Leach S, Le N, Bajdik C, Brooks-Wilson A: Genetic polymorphisms at TIMP3 are associated with survival of adenocarcinoma of the gastroesophageal junction. PLoS One 2013, 8:e59157.

60. Peters CJ, Rees JR, Hardwick RH, Hardwick JS, Vowler SL, Ong CA, Zhang C, Save $\mathrm{V}, \mathrm{O}$ 'Donovan M, Rassl D, et al: A 4-gene signature predicts survival of patients with resected adenocarcinoma of the esophagus, junction, and gastric cardia. Gastroenterology 2010, 139:1995-2004. e1915.

61. Pan JY, Ajani JA, Gu J, Gong Y, Quin A, Hung M, Wu X, Izzo JG: Association of Aurora-A (STK15) kinase polymorphisms with clinical outcome of esophageal cancer treated with preoperative chemoradiation. Cancer 2012, 118:4346-4353.

62. Chong IY, Cunningham D, Barber LJ, Campbell J, Chen L, Kozarewa I, Fenwick K, Assiotis I, Guettler S, Garcia-Murillas I, et al: The genomic landscape of oesophagogastric junctional adenocarcinoma. J Pathol 2013, 231:301-310.

63. Chirieac LR, Swisher SG, Correa AM, Ajani JA, Komaki RR, Rashid A, Hamilton SR, Wu TT: Signet-ring cell or mucinous histology after preoperative chemoradiation and survival in patients with esophageal or esophagogastric junction adenocarcinoma. Clin Cancer Res 2005, 11:2229-2236.

64. Bekkar S, Gronnier C, Messager M, Robb WB, Piessen G, Mariette C, GroupFRENCH FW: The impact of preoperative radiochemotherapy on survival in advanced esophagogastric junction signet ring cell adenocarcinoma. Ann Thorac Surg 2014, 97:303-310.

65. Enlow JM, Denlinger CE, Stroud MR, Ralston JS, Reed CE: Adenocarcinoma of the esophagus with signet ring cell features portends a poor prognosis. Ann Thorac Surg 2013, 96:1927-1932.

doi:10.1186/1748-717X-9-45

Cite this article as: Cellini et al: Clinical management of gastroesophageal junction tumors: past and recent evidences for the role of radiotherapy in the multidisciplinary approach. Radiation Oncology 2014 9:45.

\section{Submit your next manuscript to BioMed Central and take full advantage of:}

- Convenient online submission

- Thorough peer review

- No space constraints or color figure charges

- Immediate publication on acceptance

- Inclusion in PubMed, CAS, Scopus and Google Scholar

- Research which is freely available for redistribution

Submit your manuscript at www.biomedcentral.com/submit
() Biomed Central 